\title{
Thrombectomy from superior mesenteric vein in treatment of small intestine gangrene
}

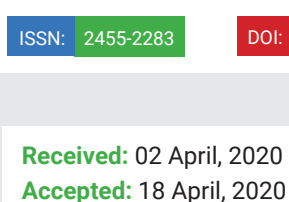

Published: 20 April, 2020

*Corresponding author: Ihnatovich I, Educational Institution "Belarusian State Medical University", Minsk, Belarus, E-mail: ini67@inbox.ru

https://www.peertechz.com

Check for updates

\section{Ihnatovich I* and Ihnatovich K}

Educational Institution "Belarusian State Medical University”, Minsk, Belarus

The traditional definition of tissue ischemia-a decreased level of oxygen deliverability by bloodstream that results in cell hypoxia. Anatomical and functional hindrance to blood flow is the basis of tissue hypoperfusion. Arterial, venous and functional disturbances in blood circulation lead to acute intestinal ischemia. In $85-90 \%$ of cases acute mesenterial ischemia was caused by arterial reasons: thrombosis or embolism. Venous thrombosis is responsible for $10 \%-15 \%$ of acute mesenterial ischemia cases. Hereditary or acquired coagulopathy disorders-deficiency of protein C or ATIII-are at the core of mesenteric veins primary thrombosis. The first publication describing convalescence after resection of necrotic bowel caused by mesenteric vein thrombosis was by Elliot in 1895 [1]. In the most of cases mesenterial ischemia is caused by superior mesenteric vein thrombosis that sometimes extends over portal vein. [2]. The following example shows specific treatment technique for this difficult pathology. The treatment protocol was approved by the University ethics committee (No. 20140451) and patient signed a written consent to surgery.

A 71 year old woman presented to the emergency department with epigastric pain of one day duration, nausea and single vomiting. The cause of pain syndrome was not revealed by laboratory methods, abdominal X-ray, ultrasonography and fibrogastroduodenoscopy. In 24 hours pain syndrome was arrested and ache did not resume; patient was discharged for outpatient treatment. A day later she was hospitalized once again due to recurrence of abdominal pain. On physical examination moderate abdominal distention was observed. Dilated loops of small bowel and moderate amount of liquid in abdominal cavity were detected by repeated ultrasonogram. The spiral CT of abdomen with bolus contrast enhancement was planned in few hours, but the condition of the patient deteriorated. Abdominal pain diminished while peritoneal signs appeared in hypogastric region. Blood pressure was 100/60. On rectal examination blood in stool was detected.
The indications for immediate laparotomy were identified. The laparotomy revealed moderate amount of serohemorrhagic exsudate and hemorrhagic gangrene of small intestine. Intestine wall was edematic, $40 \mathrm{~cm}$ distally from Treitz's ligament part of small intestine was of dark-purple color, with absent peristalsis and hyperemic mesentery. The length of hemorrhagic gangrene was approximatively 1 meter. Resection of necrotic bowel was performed (Specimen 1). Proximal bound of gangrene was within the limits of jejunum therefore it was extremely objectionable to make jejunostomy even for a short period of time. Making anastomosis after bowel resection was rather risky because of edematic bowel wall. Performing of safe primary anastomosis demanded restore blood flow in bowel wall. Having performed section of necrotic bowel, mesentery veins with organized thrombotic masses in them were found. These veins were used as access to superior mesenteric vein system (Figure 1). Thrombectomy from superior mesenteric vein and its distant branches was performed using the Fogarty catheter (Figure 2).

30 minutes after thromboectomy active peristalsis and diminished swelling were observed in the remaining part of small bowl. Diameter of proximal edge remained two times bigger than the distal one. Superior mesenteric artery pulsation was satisfactory, without systolic murmurs over it. Stapled Jejuno-jejuna side-to-side anastomosis was performed, followed by control of haemostasis, lavage, sanation and draining of abdominal cavity. Operational wound was sewed up. Figure 2. shows the operation scheme.

The microscopic picture of specimen \#1. Diffuse extravasation and leukocyte infiltration of the bowel wall. The mucosa was necrotic, the serous coat is covered with fibrin and leukocytes. Mesenteric vessels were plethoric. The microscopic picture of specimen \#2. Histologic features of thrombus. 


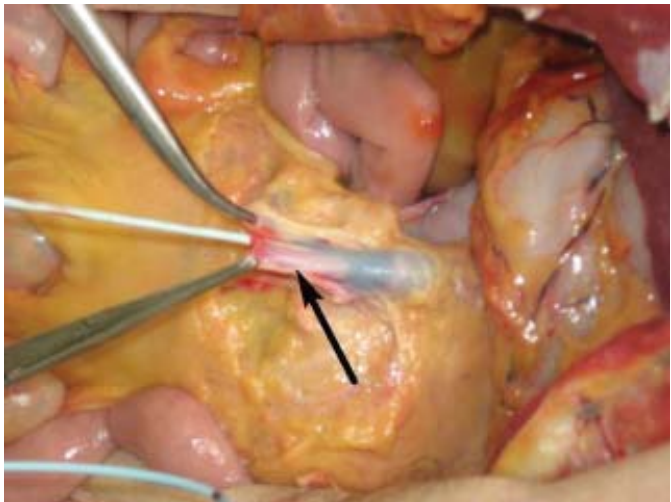

Figure 1: Vein of intestine mesentery (arrow) as access for thrombectomy from superior mesenteric vein (cadaveric model).

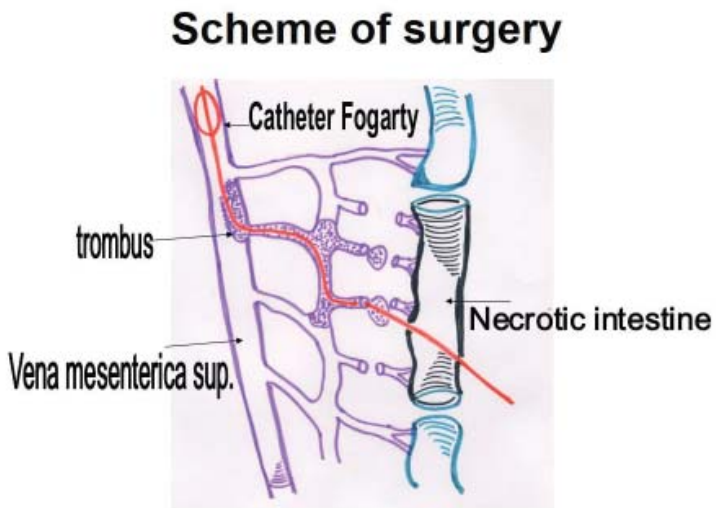

Figure 2: Graphic representation of the site of surgical procedure.
Diagnosis after surgery: Segmental venous thrombosis in system of superior mesenteric vein. Hemorrhagic gangrene of small intestine. Peritonitis.

Postoperative period was uncomplicated. Recovery of peristalsis was observed on the second day after surgery, stool of normal color was passed on the 4th day. Postoperation wound healed by primary. Patient received longterm warfarin therapy and had a good quality of life during 5 years follow up.

This clinical case demonstrates the difficulties in diagnosis of mesenteric veins thrombosis until bowel gangrene and peritonitis develops. Moreover, it emphasizes the possibility of surgical thrombectomy from superior mesenteric vein. Trombectomy performs a favorable impact on bowel blood circulation and allows making primary anastomosis after resection. Thrombectomy prevents from progression of thrombosis and bowel necrosis. Thrombosed veins of mesentery of affected bowel, discovered during its mobilization and resection, can be used as access to superior mesenteric vein system. This method of thrombectomy is simple and effective.

\section{References}

1. Elliot JW (1895) II. The operative relief of gangrene of intestine due to occlusion of the mesenteric vessels. Ann Surg 21: 9-23. Link: https://bit.ly/34Jts4t

2. Acosta S, Bjork M (2014) Mesenteric vascular disease: venous thrombosis In: Cronenwett J, editor. Rutherford's vascular surgery. $8^{\text {th }}$ ed. Saunder 2414 2420. Link: https://bit.ly/2zbUc1J

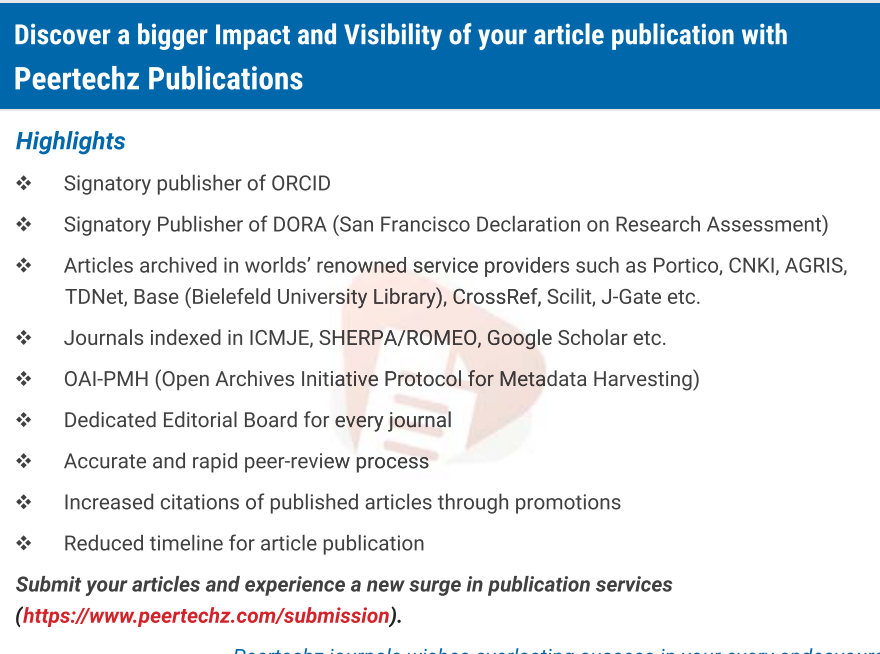

Peertechz journals wishes everlasting success in your every endeavours.

Copyright: (C) 2020 Ihnatovich I, et al. This is an open-access article distributed under the terms of the Creative Commons Attribution License, which permits unrestricted use, distribution, and r eproduction in any medium, provided the original author and source are credited. 